\title{
Clinical outcomes after one anastomosis gastric bypass versus sleeve gastrectomy in super-super-obese patients
}

\author{
Sophia M.-T. Schmitz ${ }^{1}$ - . Patrick H. Alizai ${ }^{1}$. Andreas Kroh ${ }^{1}$. Sandra Schipper ${ }^{1}$. Jonathan F. Brozat ${ }^{2}$. \\ Andreas Plamper ${ }^{4}$. Ulf P. Neumann ${ }^{1,3} \cdot$ Karl Rheinwalt $^{4} \cdot$ Tom F. Ulmer $^{1,3}$
}

Received: 23 June 2021 / Accepted: 17 October 2021 / Published online: 26 October 2021

(c) The Author(s) 2021

\begin{abstract}
Background Bariatric surgery in super-super-obese (SSO) patients remains a continuous challenge due to intraabdominal fat masses, higher liver volume and existing comorbidities. A convenient procedure in SSO patients is one anastomosis gastric bypass (OAGB). The aim of this study was to compare the outcome of SSO patients undergoing OAGB in comparison to laparoscopic sleeve gastrectomy (LSG).

Methods We retrospectively reviewed data from SSO patients who underwent OAGB and LSG in our institution between 2008 and 2020. Primary endpoints included percentage total body weight loss and percentage BMI loss at 12, 24, and 36 months after the operation. Secondary endpoints were perioperative complications, procedure length, length of hospital stay and outcome of comorbidities.

Results 243 patients were included in this study. 93 patients underwent LSG and 150 underwent OAGB. At any of the time points evaluated, weight loss in patients after OAGB was greater than in LSG patients, while procedure length was significantly shorter for OAGB than LSG $(81.4$ vs. $92.1 \mathrm{~min}, p$-value $<0.001)$. Additionally, mean length of hospital stay was shorter in the OAGB group (3.4 vs. 4.5 days, $p$-value $<0.001$ ). There were more severe complications (Clavien-Dindo $\geq 3 \mathrm{a}$ ) in the LSG group $(11.8 \%$ vs $2.7 \%, p$-value $=0.005)$.

Conclusion In this retrospective analysis, OAGB was superior to LSG in terms of weight loss in SSO patients. Procedure length and hospital stay were shorter after OAGB in comparison to LSG and there were fewer severe complications. OAGB can therefore be regarded a safe and effective treatment modality for SSO patients.
\end{abstract}

Keywords Bariatric surgery $\cdot$ Super-super-obese $\cdot \mathrm{SSO} \cdot$ One anastomosis gastric bypass $\cdot$ OAGB

Karl Rheinwalt and Tom F. Ulmer have contributed equally to this work.

Sophia M.-T. Schmitz

sopschmitz@ukaachen.de

Patrick H. Alizai

palizai@ukaachen.de

Andreas Kroh

akroh@ukaachen.de

Sandra Schipper

sschipper@ukaachen.de

Jonathan F. Brozat

jbrozat@ukaachen.de

Andreas Plamper

andreas.plamper@cellitinnen.de

Ulf P. Neumann

uneumann@ukaachen.de

Karl Rheinwalt

karlpeter.rheinwalt@cellitinnen.de
Tom F. Ulmer

fulmer@ukaachen.de

1 Department of General, Visceral- and Transplantation Surgery, RWTH Aachen University Hospital, Pauwelsstr. 30, 52074 Aachen, Germany

2 Department of Gastroenterology, Digestive Diseases and Intensive Care Medicine, RWTH Aachen University Hospital, Pauwelsstr. 30, 52074 Aachen, Germany

3 Department of Surgery, Maastricht University Medical Center, P. Debyelaan 25, 6229 HX Maastricht, The Netherlands

4 Department of Bariatric, Metabolic and Plastic Surgery, St. Franziskus-Hospital, Schönsteinstr. 63, 50825 Cologne, Germany 
Bariatric and metabolic surgery meets wide acceptance with an acceptable perioperative risk profile even in patients with higher perioperative risk profiles. Especially super-super obese (SSO) patients with a Body-Mass-Index $(\mathrm{BMI})>60 \mathrm{~kg} / \mathrm{m}^{2}$ are prone to operation risks and morbidity [1-3], caused by difficulties in exposure, a fatty liver, tension on the surgical instruments and co-existing comorbidities [4-6]. Therefore, operation time, length of hospital stay, and complication rates have been described to be higher in SSO patients in comparison to patients with a BMI $<60 \mathrm{~kg} / \mathrm{m}^{2}$ $[1,3]$.

Among the possible operative approaches in SSO patients is laparoscopic sleeve gastrectomy (LSG), as it is safe and easily feasible with acceptable weight reduction outcomes $[5,7,8]$. Furthermore, following an initial weight loss, there is the possibility of a two-stage procedure, adding laparoscopic Roux-en-Y Gastric Bypass (RYGB) or other options like Single Anastomosis Duodeno-ileal bypass with Sleeve Gastrectomy (SADI-S), Biliopancreatic Diversion with Duodenal Switch (BPD-DS) or One Anastomosis Gastric Bypass (OAGB) as a second step [5, 9]. While weight loss is superior in SADI-S or BPD-DS in comparison to RYGB after failed $\mathrm{SG}$, these methods are technically more challenging and might imply higher risks for complications $[10,11]$. RYGB has also been described as a primary procedure in SSO patients, but complication rates and length of stay usually have been reported to be significantly higher than after LSG $[5,7,12]$. A suitable approach in SSO patients is the One Anastomosis Gastric Bypass (OAGB), that is comparable to LSG in safety and might yield superior results regarding weight loss and remission of comorbidities [13-20]. OAGB has been reported to be safe in SSO patients with a BMI $>60 \mathrm{~kg} / \mathrm{m}^{2}[13,21]$ and seems to be even superior to RYGB in terms of reduced complications [22] and improved weight loss [21]. While data on the comparison of OAGB and LSG in patients with morbid obesity is still scarce [18, 19, 23-25], it is almost absent for SSO patients with the exception of a small retrospective cohort analysis [26].

The aim of this study was therefore to retrospectively compare OAGB and LSG in terms of weight loss and shortto mid-term outcomes in a large cohort of SSO patients.

\section{Methods}

SSO patients with a BMI $>60 \mathrm{~kg} / \mathrm{m}^{2}$ that underwent either LSG or OAGB between 2008 and 2020 were identified from a prospective surgical database.

The decision on the operative approach was taken depending on the patient's type of individual fat distribution, small bowel mobility, medications, individual preferences and bowel habits. Patients with a history of gastroesophageal reflux disease were clearly orientated towards
OAGB. Routinely all patients signed informed consent for both procedures, as the final decision of procedure was often dependent on the intraoperative conditions. Informed consent included the possible need to perform a two-stage surgery after LSG. All procedures were performed according to standardized operation techniques by a single bariatric surgeon experienced in both procedures.

All patients provided written consent to anonymized data registration in the national bariatric data base as well as statistical work-up. Ethical approval was not required due to the retrospective character of this study and the analysis of entirely pseudonymised data regarding well-established procedures. All procedures performed in studies were in accordance with the 1964 Helsinki declaration and its later amendments.

Demographic characteristics, BMI, weight, operation characteristics, as well as comorbidities and late complications were recorded prior to operation and at 3, 6, 9, 12, 24, and 36 months. Weight loss was reported as percent total body weight loss (\%TBWL) and percent BMI loss (\% BMIL). Postoperative complications were classified according to the Clavien-Dindo Classification during the hospital stay [27]. A Clavien-Dindo Score of $3 \mathrm{a}$ or higher was classified as a severe (major) complication. Partial and full remission of co-morbidities were evaluated according to the simplified Buchwald-criteria at the time points mentioned above [28]. The classification of insufficient weight loss and relevant weight regain was performed according to the criteria established by Reinhold [29].

\section{Operation characteristics}

In LSG, four $12 \mathrm{~mm}$-trocars and optionally an additional $5 \mathrm{~mm}$-trocar were placed under videoendoscopic control in the upper abdomen. Capnoperitoneum with $15 \mathrm{~mm}$ Mercury pressure was applied, in cases with insufficient working space this pressure became elevated up to $20 \mathrm{~mm}$ Mercury. With the patient in Anti-Trendelenburg-position and left lobe of the liver retracted, the greater curvature of the stomach was dissected with ultrasonic scissors (Harmonic $®$, Johnson\&Johnson) from $5 \mathrm{~cm}$ above the pylorus to the angle of His and the left crus. The gastric fundus was mobilized from the retroperitoneum as completely as possible. After introducing a $42 \mathrm{~F}$ calibration tube, the vertical dissection started distally with a black $60 \mathrm{~mm}$ cartridge using either mechanical or powered stapling device (Echelon®, Johnson\&Johnson). The further dissection until $1.5 \mathrm{~cm}$ lateral to the angle of His was performed using green, yellow and then blue cartridges, thus respecting the decreasing thickness of the proximal gastric wall. The proximal $6 \mathrm{~cm}$ of the staple line were oversewn by running absorbable suture $2-0$. Cross-sections of the staple-line and points of oozing 
were reinforced with metal clips. Routine leak test was performed. The specimen was retracted via the enlarged subcostal trocar on the left side using a specimen bag. This site was closed by a videoendoscopically applied full-thickness stitch with Vicryl ${ }^{\circledR} 1$. Routinely, a subcostal drain was placed.

In OAGB, routinely four $12 \mathrm{~mm}$-trocars and one $5 \mathrm{~mm}$ trocar were applied. With the surgeon on the right side of the patient and optional retraction of the left lobe of the liver the procedure started with dissection of supragastric adhesions lateral from the angle of His towards the upper splenic pole. Then the proximal antrum became partially dissected starting from the minor curvature with a black $60 \mathrm{~mm}$-cartridge (Echelon ${ }^{\circledR}$ mechanical or powered, Johnson\&Johnson). This was followed by retrogastric dissection of adhesions and vertical complete dissection of the stomach parallel to a intraluminal 30F-calibration tube. For this procedure, usually four to five $60 \mathrm{~mm}$ cartridges with declining stapleheight were used, forming a long and narrow pouch of 16 to $22 \mathrm{~cm}$ of length. A tension-free antecolic four to five $\mathrm{cm}$ long end-to-side-gastrojejunostomy was created after measuring a usually $250 \mathrm{~cm}$ biliopancreatic limb beginning at the ligament of Treitz. The ventral defect at the anastomosis was closed manually with 2-layers full-thickness running suture with absorbable thread 2-0. The large Petersen space was not closed. Routine blue test of pouch and anastomosis was performed, followed by clipping of cross-sections and oozing points of the staple line and subhepatic placement of a silicone drain.

\section{Statistical analysis}

Data are expressed as mean (Standard error of mean, SEM) unless otherwise indicated. Independent $T$-Test and One-way ANOVA were used to compare means between groups. Chi-square $\left(\chi^{2}\right)$ and Fisher's exact test were used for comparison of categorical data. Statistical analysis was performed with IBM SPSS v18 and GraphPad Prism v7. A $p$-value $<0.05$ was considered statistically significant.

\section{Results}

\section{Basic demographics}

A total of 243 patients (165 female, $68 \%$ ) with a mean BMI of $65.2 \mathrm{~kg} / \mathrm{m}^{2}$ (range $60.0-87.1 \mathrm{~kg} / \mathrm{m}^{2}$ ) were included in this study. OAGB was performed in 150 and LSG in 93 patients. Mean BMI was $67 \mathrm{~kg} / \mathrm{m}^{2}$ in the LSG group and $64 \mathrm{~kg} / \mathrm{m}^{2}$ in the OAGB group ( $p$-value $<0.001$ ). Apart from coronary heart disease (LSG $12.9 \%$ vs. OAGB $5.3 \%$, $p$-value $=0.037)$, comorbidities were comparable between the groups (Table 1).

\section{Operation characteristics and postoperative outcomes}

Mean operating time was significantly shorter in the OAGB group (81.4 vs. $92.1 \mathrm{~min}, p$-value $<0.001$ ). Mean hospital stay was also significantly shorter in the OAGB group (3.4 days vs. 4.5 days, $p$-value $<0.001$ ). Major postoperative complications (Clavien-Dindo-Score $\geq 3$ a) occurred more often after LSG in comparison to OAGB $(11.8 \%$ vs. $2.7 \%, p$-value $=0.005$ ). Conversion and mortality rate were zero in both groups. Occurrence of gastrointestinal ulcers was higher in the OAGB group when compared to the LSG group ( $7.3 \%$ vs. $1 \%, p$-value $=0.033)$. Postoperative dumping, reflux and malnutrition were observed rarely and showed no statistically significant differences between
Table 1 Demographic characteristics and comorbidities of patients undergoing OAGB and LSG

\begin{tabular}{|c|c|c|c|c|c|}
\hline & \multicolumn{4}{|c|}{ Operative technique } & \multirow[t]{3}{*}{$p$-value } \\
\hline & \multicolumn{2}{|c|}{ LSG $(n=93)$} & \multicolumn{2}{|c|}{ OAGB $(n=150)$} & \\
\hline & $n(\%)$ & Mean (SEM) & $n(\%)$ & Mean (SEM) & \\
\hline \multicolumn{6}{|l|}{ Sex } \\
\hline Female & $54(58.1 \%)$ & & $112(74.5 \%)$ & & 0.008 \\
\hline Age & & $41.57(1.07)$ & & $39.11(0.9)$ & 0.646 \\
\hline Weight & & $194.7(2.9)$ & & $183.7(1.8)$ & 0.006 \\
\hline BMI & & $66.91(0.6)$ & & $64.14(0.3)$ & $<0.001$ \\
\hline Sleep apnea & $69(74.2 \%)$ & & $113(75.3 \%)$ & & 0.444 \\
\hline T2DM & $42(45.7 \%)$ & & $51(34.0 \%)$ & & 0.07 \\
\hline Orthopedic comorbidities & $91(97.8 \%)$ & & $142(94.7 \%)$ & & 0.225 \\
\hline CHD & $12(12.9 \%)$ & & $8(5.3 \%)$ & & 0.037 \\
\hline Hypertension & $69(74.2 \%)$ & & $98(65.3 \%)$ & & 0.148 \\
\hline
\end{tabular}

Bold values indicate statistical significance

$B M I$ body mass index, $C H D$ coronary heart disease, $L S G$ laparoscopic sleeve gastrectomy, $O A G B$ one anastomosis gastric bypass, SEM standard error of the mean, T2DM type 2 diabetes mellitus 
Table 2 Characteristics of operation and postoperative course in patients undergoing OAGB and LSG

\begin{tabular}{|c|c|c|c|c|c|}
\hline & \multicolumn{4}{|c|}{ Operative technique } & \multirow[t]{3}{*}{$p$-value } \\
\hline & \multicolumn{2}{|l|}{ LSG $(n=93)$} & \multicolumn{2}{|c|}{ OAGB $(n=150)$} & \\
\hline & Mean (SEM) & $n(\%)$ & Mean (SEM) & $n(\%)$ & \\
\hline \multicolumn{6}{|l|}{$\begin{array}{l}\text { Operation characteristics and early } \\
\text { postoperative complications }\end{array}$} \\
\hline Operating Time & $92.08(3.1)$ & & $81.36(1.6)$ & & $<0.001$ \\
\hline Conversion & & $0(0 \%)$ & & $0(0 \%)$ & \\
\hline Mortality & & $0(0 \%)$ & & $0(0 \%)$ & \\
\hline Length of Hospital Stay & $4.53(0.2)$ & & $3.44(0.1)$ & & $<0.001$ \\
\hline \multicolumn{6}{|l|}{ Clavien-Dindo Complication Score } \\
\hline$\leq 3$ & & $82(88.2 \%)$ & & $146(97.3 \%)$ & $\mathbf{0 . 0 0 5}$ \\
\hline$\geq 3$ & & $11(11.8 \%)$ & & $4(2.7 \%)$ & \\
\hline \multicolumn{6}{|l|}{ Late postoperative complication } \\
\hline Malnutrition & & $14(30.4 \%)$ & & $32(69.6 \%)$ & 0.225 \\
\hline Insufficient weight loss/weight regain & & $28(66.7 \%)$ & & $14(33.3 \%)$ & $<0.001$ \\
\hline Ulcer & & $1(1 \%)$ & & $11(7.3 \%)$ & $\mathbf{0 . 0 3 3}$ \\
\hline Dumping & & $0(0 \%)$ & & $3(2 \%)$ & 0.288 \\
\hline Reflux & & $10(10.8 \%)$ & & $9(6.0 \%)$ & 0.180 \\
\hline
\end{tabular}

Bold values indicate statistical significance

$L S G$ laparoscopic sleeve gastrectomy, $O A G B$ one anastomosis gastric bypass, SEM standard error of the mean, $T 2 D M$ type 2 diabetes mellitus groups. See Table 2 for a comparison of the operative outcomes in the two groups.

\section{Weight loss}

The follow-up-rate after 12 months was 65\% in OAGB and 59\% in LSG, after 24 months 45 and 32\%, resp., and after 36 months 23 and 17\%, resp. Following OAGB, \%TBWL and \%BMIL were significantly higher compared with LSG at all time points with the exception of \%BMIL after three months (Figs. 1, 2). In comparison to OAGB, significantly more patients that underwent LSG suffered from insufficient weight loss or weight regain after LSG (14 vs. 28 patients, $p$-value $<0.001)$

\section{Comorbidities}

There was no difference in remission or improvement of comorbidities (T2DM, sleep apnea, orthopedic comorbidities) with the exception of arterial hypertension, where remission rate was higher after OAGB than after LSG after 12 months ( $p$-value $=0.048$; Fig. 3 ).

\section{Discussion}

The management of SSO patients is a persistent surgical challenge due to difficult intraoperative conditions and associated increase in perioperative risks. The ideal

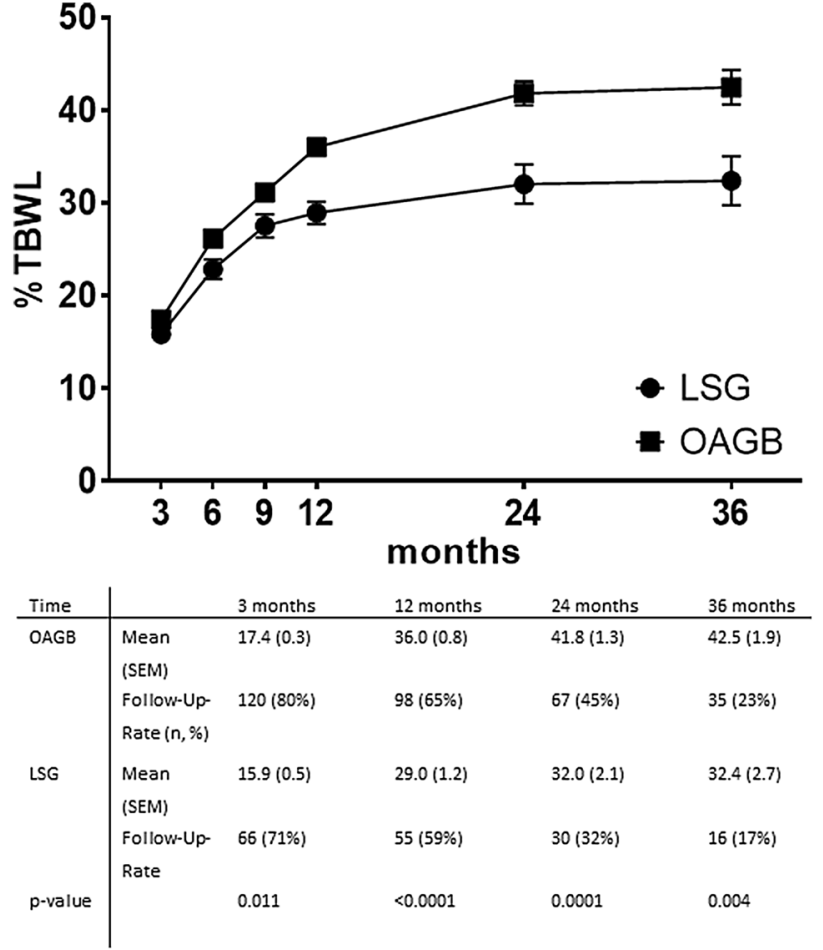

Fig. 1 Weight loss outcomes in patients undergoing OAGB and LSG; $L S G$ laparoscopic sleeve gastrectomy, $O A G B$ one anastomosis gastric bypass, $T B W L$ total body weight loss; there was a significant difference in TBWL at all time points 


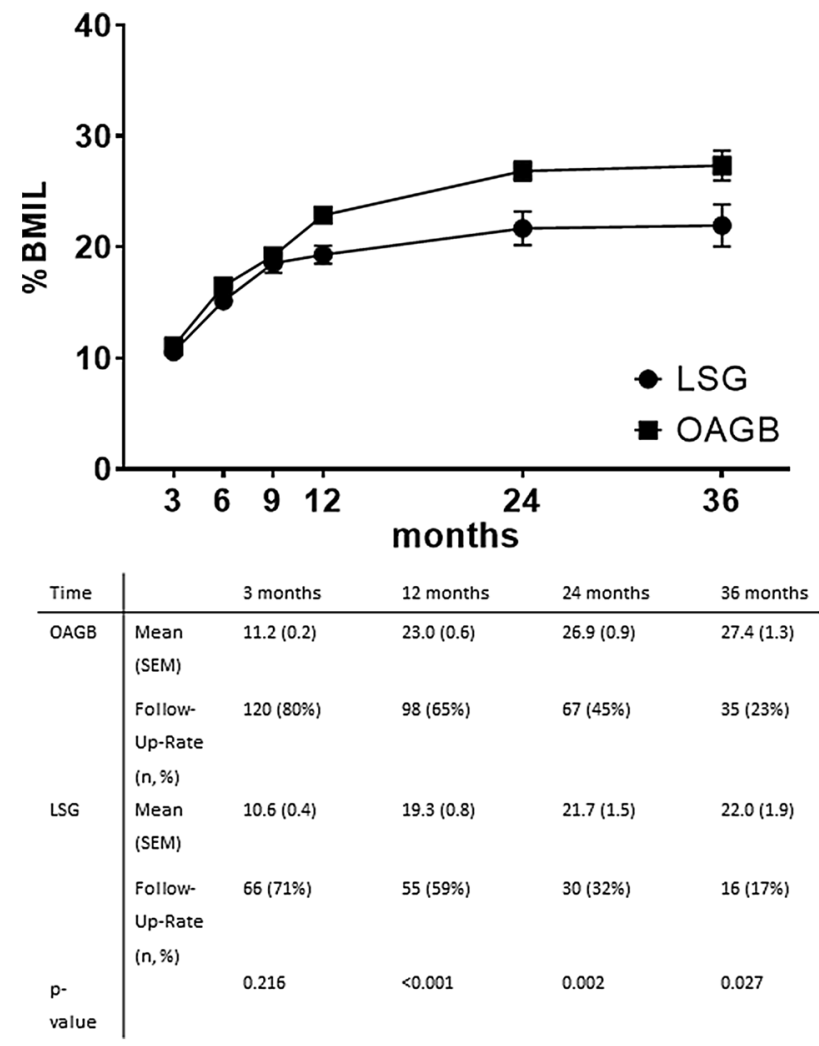

Fig. 2 Weight loss outcomes in patients undergoing OAGB and LSG; $L S G$ laparoscopic sleeve gastrectomy, $O A G B$ one anastomosis gastric bypass, \%BMIL percent BMI Loss

operative approach in these patients remains a subject of intense discussions. Up to now, most studies concerning bariatric surgery in SSO patients focussed on LSG and RYGB [1, 5-7, 12, 30]. As OAGB is performed less frequently in comparison to LSG and RYGB, evidence on patient-oriented outcomes following OAGB remains scarce $[13,26]$. Moreover, most publications concerning results of OAGB focus on cohorts of patients with a wide range BMI-levels and do not focus exclusively on SSO patients [14-20, 22, 23, 25]. Parmar et al. compared RYGB with OAGB in SSO patients [21] and Singla et al. compared LSG with OAGB in patients with a BMI $>50 \mathrm{~kg} / \mathrm{m}^{2}$ [24]. A review of Parmar et al. focused on OAGB versus LSG and RYGB in patients with a BMI $>50 \mathrm{~kg} / \mathrm{m}^{2}$ [31]. Peraglie et al. examined a cohort of SSO patients receiving OAGB in a single center study, showing effectiveness and safety of this procedure in SSO patients [13]. In summary, both the underrepresentation of the procedure and the rareness of SSO patients add to most published studies being underpowered.

In this study, the outcome of 243 SSO patients was evaluated and OAGB resulted in superior weight loss in comparison to LSG while requiring shorter operation times
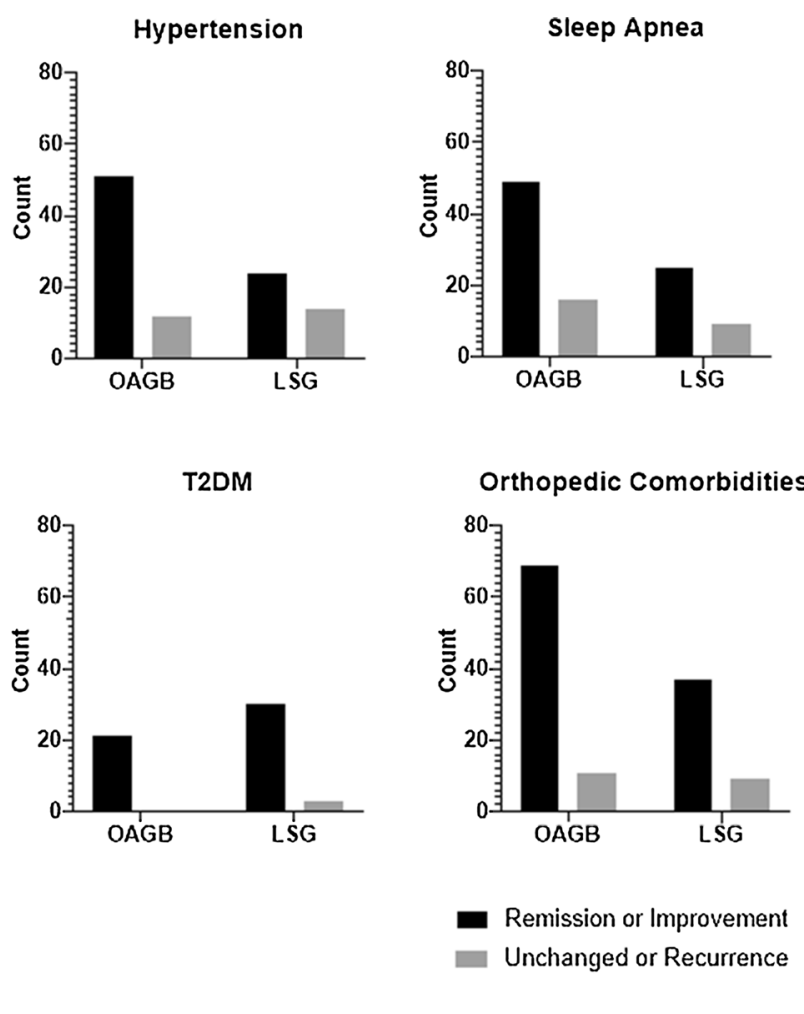

Fig. 3 Comorbidity outcomes after 12 months of patients undergoing OAGB and LSG; $L S G$ laparoscopic sleeve gastrectomy, $O A G B$ one anastomosis gastric bypass, SEM standard error of the mean, $T 2 D M$ type 2 diabetes mellitus; $\chi^{2}$-Test revealed a significant difference for remission of Hypertension between OAGB and LSG ( $p$-value 0.048), for other comorbidities differences were not significant

and resulting in shorter lengths of hospital stay. Of interest, 28 patients in the LSG group compared to 14 patients in the OAGB group suffered from insufficient weight loss or weight regain after the operation, favoring possible superior short- to mid-term effects of OAGB in comparison to LSG in SSO patients.

Adding to this possible superiority, other publications including morbidly obese patients similarly report on higher weight loss after OAGB in comparison to LSG [18, 24, 32]. Admittedly, Kular et al. have reported a similar \%EWL in patients after OAGB compared to LSG. However, these patients had a mean BMI of only $44 \mathrm{~kg} / \mathrm{m}^{2}$ (OAGB) and $42 \mathrm{~kg} / \mathrm{m}^{2}$ (LSG) and the results therefore seem barely comparable to our study [23]. In SSO patients, Parmar et al. showed superior weight loss of OAGB in comparison to RYGB [21].

Procedure length was significantly shorter for OAGB in comparison to LSG in our study (81.4 vs. $92.1 \mathrm{~min}$, $p$-value $<0.001)$. There is divergent data on operation time for both procedures. A recent meta-analysis found no difference between LSG and OAGB in patients with a mean BMI of $41.8 \mathrm{~kg} / \mathrm{m}^{2}$ and $40.8 \mathrm{~kg} / \mathrm{m}^{2}$, respectively [18]. In general, operation time for bariatric procedures in SSO patients is 
longer than in non-SSO patients $[1,21]$. In contrast to our study, Madhok et al. found significantly shorter operation times for LSG (75 $\mathrm{min}$ ) in comparison toOAGB (92 $\mathrm{min}$ ) in SSO patients [26]. These contradicting findings might partially be explainable by the higher BMI of our LSG patients at the time of the operation. Furthermore, over-sewing of staple lines and the need of specimen extraction might add to a longer operation time in LSG patients.

Postoperative complication rates have been reported in $15.1 \%$ (RYBG) and $4.8 \%$ (LSG) in SSO patients [12], while complication rates in OAGB generally have been reported to be less than $3 \%$ in patients with BMI $>50 \mathrm{~kg} / \mathrm{m}^{2}$ [31]. In our study, we report a rate of severe complications (ClavienDindo $\geq 3$ a) in $11.8 \%$ (LSG) compared to $2.7 \%$ (OAGB) for SSO patients. In a large meta-analysis, the risk of postoperative leakage was higher after LSG compared to OAGB, while the risk of malnutrition and ulcers was increased after OAGB [18]. While we can confirm these findings in terms of a higher perioperative complication rate after LSG and higher risk of ulcers after OAGB, we did not find an increased rate of reported deficiencies for albumin, iron, calcium or vitamins after OAGB.

Another noteworthy finding is the higher rate of remission or improvement of arterial hypertension after OAGB, while for other comorbidities the differences was not significant. Other studies report no differences in resolution of comorbidities [25].

Inherent to its retrospective design, the present study is limited by sample size and study period. The follow-up rate at three years is exceptionally low and has to be considered carefully. However, we report higher follow-up rates than other studies on the same subject report [12]. Second, due to the fact that the final decision on which procedure to perform was made intraoperatively there might have been a tendency to perform LSG in challenging cases. Notwithstanding these limitations, this study is to our knowledge the largest one so far to compare OAGB and LSG in SSO patients, including therefore manifold clinical implications.

\section{Conclusion}

We found significantly higher weight loss, lower complication rate, and similar remission of comorbidities in OAGB compared to LSG in SSO patients. Additionally, both procedure length and length of hospital stay were shorter after OAGB. Taken into account the limitations of this retrospective analysis, OAGB can be considered a safe and effective option in the treatment of SSO patients and can possibly even be considered superior to LSG in these patients.
Funding Open Access funding enabled and organized by Projekt DEAL.

\section{Declarations}

Disclosures Sophia M.-T. Schmitz, Patrick H. Alizai, Andreas Kroh, Sandra Schipper, Jonathan F. Brozat, Andreas Plamper, Ulf P. Neumann, Karl Rheinwalt and Tom F. Ulmer have no conflicts of interest or financial ties to disclose.

Open Access This article is licensed under a Creative Commons Attribution 4.0 International License, which permits use, sharing, adaptation, distribution and reproduction in any medium or format, as long as you give appropriate credit to the original author(s) and the source, provide a link to the Creative Commons licence, and indicate if changes were made. The images or other third party material in this article are included in the article's Creative Commons licence, unless indicated otherwise in a credit line to the material. If material is not included in the article's Creative Commons licence and your intended use is not permitted by statutory regulation or exceeds the permitted use, you will need to obtain permission directly from the copyright holder. To view a copy of this licence, visit http://creativecommons.org/licenses/by/4.0/.

\section{References}

1. Stephens DJ, Saunders JK, Belsley S, Trivedi A, Ewing DR, Iannace V et al (2008) Short-term outcomes for super-super obese $\left(\right.$ BMI $>$ or $=60 \mathrm{~kg} / \mathrm{m}^{2}$ ) patients undergoing weight loss surgery at a high-volume bariatric surgery center: laparoscopic adjustable gastric banding, laparoscopic gastric bypass, and open tubular gastric bypass. Surg Obes Relat Dis 4(3):408-415

2. Ballantyne GH, Svahn J, Capella RF, Capella JF, Schmidt HJ, Wasielewski A et al (2004) Predictors of prolonged hospital stay following open and laparoscopic gastric bypass for morbid obesity: body mass index, length of surgery, sleep apnea, asthma, and the metabolic syndrome. Obes Surg 14(8):1042-1050

3. Wilkinson KH, Helm M, Lak K, Higgins RM, Gould JC, Kindel TL (2019) The risk of post-operative complications in super-super obesity compared to super obesity in accredited bariatric surgery centers. Obes Surg 29(9):2964-2971

4. Parikh MS, Shen R, Weiner M, Siegel N, Ren CJ (2005) Laparoscopic bariatric surgery in super-obese patients (BMI>50) is safe and effective: a review of 332 patients. Obes Surg 15(6):858-863

5. Arapis K, Macrina N, Kadouch D, Ribeiro Parenti L, Marmuse JP, Hansel B (2019) Outcomes of Roux-en-Y gastric bypass versus sleeve gastrectomy in super-super-obese patients (BMI $>/=60$ $\mathrm{kg} / \mathrm{m}\left({ }^{2}\right)$ ): 6-year follow-up at a single university. Surg Obes Relat Dis 15(1):23-33

6. Nguyen NT, Ho HS, Palmer LS, Wolfe BM (1999) Laparoscopic Roux-en-Y gastric bypass for super/super obesity. Obes Surg 9(4):403-406

7. Gonzalez-Heredia R, Sanchez-Johnsen L, Valbuena VS, Masrur M, Murphey M, Elli E (2016) Surgical management of supersuper obese patients: Roux-en-Y gastric bypass versus sleeve gastrectomy. Surg Endosc 30(5):2097-2102

8. Clinical Issues Committee of the American Society for M, Bariatric S (2010) Updated position statement on sleeve gastrectomy as a bariatric procedure. Surg Obes Relat Dis 6(1):1-5

9. Regan JP, Inabnet WB, Gagner M, Pomp A (2003) Early experience with two-stage laparoscopic Roux-en-Y gastric bypass as an alternative in the super-super obese patient. Obes Surg 13(6):861-864 
10. Dijkhorst PJ, Boerboom AB, Janssen IMC, Swank DJ, Wiezer RMJ, Hazebroek EJ et al (2018) Failed sleeve gastrectomy: single anastomosis duodenoileal bypass or Roux-en-Y gastric bypass? A multicenter cohort study. Obes Surg 28(12):3834-3842

11. Li S, Jiao S, Zhang S, Zhou J (2021) Revisional surgeries of laparoscopic sleeve gastrectomy. Diabetes Metab Syndr Obes 14:575-588

12. Serrano OK, Tannebaum JE, Cumella L, Choi J, Vemulapalli P, Scott Melvin W et al (2016) Weight loss outcomes and complications from bariatric surgery in the super super obese. Surg Endosc 30(6):2505-2511

13. Peraglie C (2008) Laparoscopic mini-gastric bypass (LMGB) in the super-super obese: outcomes in 16 patients. Obes Surg 18(9):1126-1129

14. Noun R, Skaff J, Riachi E, Daher R, Antoun NA, Nasr M (2012) One thousand consecutive mini-gastric bypass: short- and longterm outcome. Obes Surg 22(5):697-703

15. Lee WJ, Yu PJ, Wang W, Chen TC, Wei PL, Huang MT (2005) Laparoscopic Roux-en-Y versus mini-gastric bypass for the treatment of morbid obesity: a prospective randomized controlled clinical trial. Ann Surg 242(1):20-28

16. Rutledge $\mathrm{R}$ (2001) The mini-gastric bypass: experience with the first 1,274 cases. Obes Surg 11(3):276-280

17. Rutledge R, Walsh TR (2005) Continued excellent results with the mini-gastric bypass: six-year study in 2,410 patients. Obes Surg 15(9):1304-1308

18. Wu C, Bai R, Yan W, Yan M, Song M (2020) Clinical outcomes of one anastomosis gastric bypass versus sleeve gastrectomy for morbid obesity. Obes Surg 30(3):1021-1031

19. Wang FG, Yu ZP, Yan WM, Yan M, Song MM (2017) Comparison of safety and effectiveness between laparoscopic mini-gastric bypass and laparoscopic sleeve gastrectomy: a meta-analysis and systematic review. Medicine 96(50):e8924

20. Plamper A, Lingohr P, Nadal J, Rheinwalt KP (2017) Comparison of mini-gastric bypass with sleeve gastrectomy in a mainly superobese patient group: first results. Surg Endosc 31(3):1156-1162

21. Parmar C, Abdelhalim MA, Mahawar KK, Boyle M, Carr WRJ, Jennings $\mathrm{N}$ et al (2017) Management of super-super obese patients: comparison between one anastomosis (mini) gastric bypass and Roux-en-Y gastric bypass. Surg Endosc 31(9):3504-3509

22. Rheinwalt KP, Plamper A, Ruckbeil MV, Kroh A, Neumann UP, Ulmer TF (2020) One anastomosis gastric bypass-minigastric bypass (OAGB-MGB) versus Roux-en-Y Gastric Bypass
(RYGB)-a mid-term cohort study with 612 patients. Obes Surg 30(4):1230-1240

23. Kular KS, Manchanda N, Rutledge R (2014) Analysis of the five-year outcomes of sleeve gastrectomy and mini gastric bypass: a report from the Indian sub-continent. Obes Surg 24(10):1724-1728

24. Singla V, Aggarwal S, Singh B, Tharun G, Katiyar V, Bhambri A (2019) Outcomes in super obese patients undergoing one anastomosis gastric bypass or laparoscopic sleeve gastrectomy. Obes Surg 29(4):1242-1247

25. Shivakumar S, Tantia O, Goyal G, Chaudhuri T, Khanna S, Ahuja A et al (2018) LSG vs MGB-OAGB-3 year follow-up data: a randomised control trial. Obes Surg 28(9):2820-2828

26. Madhok B, Mahawar KK, Boyle M, Carr WR, Jennings N, Schroeder N et al (2016) Management of super-super obese patients: comparison between mini (one anastomosis) gastric bypass and sleeve gastrectomy. Obes Surg 26(7):1646-1649

27. Dindo D, Demartines N, Clavien PA (2004) Classification of surgical complications: a new proposal with evaluation in a cohort of 6336 patients and results of a survey. Ann Surg 240(2):205-213

28. Buchwald H, Estok R, Fahrbach K, Banel D, Jensen MD, Pories WJ et al (2009) Weight and type 2 diabetes after bariatric surgery: systematic review and meta-analysis. Am J Med 122(3):248-56 e5

29. Reinhold RB (1982) Critical analysis of long term weight loss following gastric bypass. Surg Gynecol Obstet 155(3):385-394

30. Mehaffey JH, LaPar DJ, Turrentine FE, Miller MS, Hallowell PT, Schirmer BD (2015) Outcomes of laparoscopic Roux-en-Y gastric bypass in super-super-obese patients. Surg Obes Relat Dis 11(4):814-819

31. Parmar CD, Bryant C, Luque-de-Leon E, Peraglie C, Prasad $\mathrm{A}$, Rheinwalt $\mathrm{K}$ et al (2019) One anastomosis gastric bypass in morbidly obese patients with BMI $>/=50 \mathrm{~kg} / \mathrm{m}^{2}$ ): a systematic review comparing it with Roux-En-Y gastric bypass and sleeve gastrectomy. Obes Surg 29(9):3039-3046

32. Jain M, Tantia O, Goyal G, Chaudhuri T, Khanna S, Poddar A et al (2021) LSG vs MGB-OAGB: 5-year follow-up data and comparative outcome of the two procedures over long term-results of a randomised control trial. Obes Surg 31(3):1223-1232

Publisher's Note Springer Nature remains neutral with regard to jurisdictional claims in published maps and institutional affiliations. 